\title{
Brain metastases of parathyroid carcinoma: Review of the literature and a case report
}

\author{
Hana Studentova ${ }^{\mathrm{a}}$, Bohuslav Melichar ${ }^{\mathrm{a}, \mathrm{e}}$, Jan Cincibuch ${ }^{\mathrm{a}}$, Milan Kaminek ${ }^{\mathrm{b}}$, Zdenek Frysakc, Marie Geierova ${ }^{\mathrm{d}}$, Jiri Klein ${ }^{\mathrm{a}}$
}

Background. Parathyroid carcinoma is a rare tumor typically presenting with marked elevations of serum calcium concentrations and associated renal and skeletal symptoms. Parathyroid carcinoma grows slowly, but may recur in regional lymph nodes, and, in about $25 \%$ of patients, metastasizes to the lungs.

Method. Description of a new case and review of the literature.

Results. We present here a patient with parathyroid carcinoma that had aggressive biological behavior with synchronous lung metastases and manifestation of brain metastases 18 month after the initial diagnosis and review earlier reports on this rare presentation. These metastases could be detected with $\left[{ }^{18} \mathrm{~F}\right]$ fluorodeoxyglucose positron-emission tomography/computed tomography as well as with ${ }^{99 m}$ technetium-sestamibi scan.

Conclusions. Except for surgery in case of isolated solitary metastases, therapeutic options in patients with brain metastases of parathyroid carcinoma are currently very limited.

Key words: parathyroid carcinoma, brain metastases, hypercalcemia, ${ }^{99 m}$ technetium-sestamibi

Received: October 14, 2014; Accepted: January 12, 2015; Available online: February 10, 2015 http://dx.doi.org/10.5507/bp.2015.001

${ }^{a}$ Department of Oncology, Faculty of Medicine and Dentistry, Palacky University Olomouc and University Hospital Olomouc, Czech Republic ${ }^{b}$ Department of Nuclear Medicine, Faculty of Medicine and Dentistry, Palacky University Olomouc and University Hospital Olomouc 'Department of Internal Medicine III - Nephrology, Rheumatology and Endocrinology, Faculty of Medicine and Dentistry, Palacky University Olomouc and University Hospital Olomouc

${ }^{d}$ Department of Pathology, Faculty of Medicine and Dentistry, Palacky University Olomouc and University Hospital Olomouc eInstitute of Molecular and Translational Medicine, Faculty of Medicine and Dentistry, Palacky University Olomouc and University Hospital Olomouc

Corresponding author: Bohuslav Melichar, e-mail: bohuslav.melichar@fnol.cz

\section{INTRODUCTION}

Parathyroid carcinoma is a very rare tumor representing only about $0.005 \%$ of all cancers ${ }^{1}$. Among patients with primary hyperparathyroidism, the estimated incidence of parathyroid carcinoma was reported to range between $0.1 \%$ and $4.6 \%$, but is probably well below $1 \%$ in Western countries ${ }^{2,3}$. Typically, parathyroid carcinoma grows slowly, but the clinical course of the disease may be variable, with 5-year survival rates around $85 \%$ and 10 -year survival rate ranging between $49 \%$ and $77 \%$, respectively ${ }^{1,4}$. Surgery that comprises resection of the tumor and en block resection of the soft tissues remains the only effective treatment of this rare tumor ${ }^{3}$. However, up to $40-60 \%$ of patients treated with radical surgery will ultimately experience disease recurrence ${ }^{3,4}$. Intracranial metastases of parathyroid carcinoma are extremely rare and only few cases have been reported. We present here an additional case of a patient with parathyroid carcinoma that was complicated by an early manifestation of lung and brain metastases and we review the literature on this topic.

\section{Case Report}

A 62-year-old woman, with no history of significant comorbidity, presented in December 2006 with dysphonia and neck mass. On sonographic examination, a mass in the left lobe of the thyroid gland was evident. Fine needle aspiration cytology indicated the presence of suspicious malignant cells. The computed tomography (CT) scans revealed enlarged left lobe of the thyroid gland with suspected cervical lymph node involvement. Because of suspected thyroid malignancy, the patient was referred for surgery and on January 25, 2007 underwent total thyroidectomy and removal of the macroscopically involved lymph nodes. Unexpectedly, on histological examination poorly differentiated parathyroid carcinoma with metastatic involvement of lymph nodes was diagnosed (Fig. 1). Because the diagnosis of parathyroid carcinoma was not initially suspected, only limited testing for biochemical biomarkers of the tumor was performed. Serum calcium concentration one week before surgery was slightly elevated at $2.77 \mathrm{mmol} / \mathrm{L}$ (normal range $2.10-2.90 \mathrm{mmol} / \mathrm{L}$ ). Serum parathyroid hormone concentration two weeks after surgery was $37 \mathrm{ng} / \mathrm{L}$ (normal range 10-69 ng/L). On February 23, 2007, whole body $\left[{ }^{18} \mathrm{~F}\right]$ fluorodeoxyglucose (FDG) positron-emission tomography (PET)/CT detected multiple metastases bilaterally in the lungs and also bilaterally in the cervical lymph nodes. The patient was then treated by 8 cycles of systemic doxorubicin. Follow-up PET/CT examinations in May 2007 (Fig. 2) and August 2007 demonstrated significant regression (partial response) of lung and lymph node metastases, and in August 2007 only 3 residual lung metastases were evident. In October 2007, the patient had thoracoscopic 

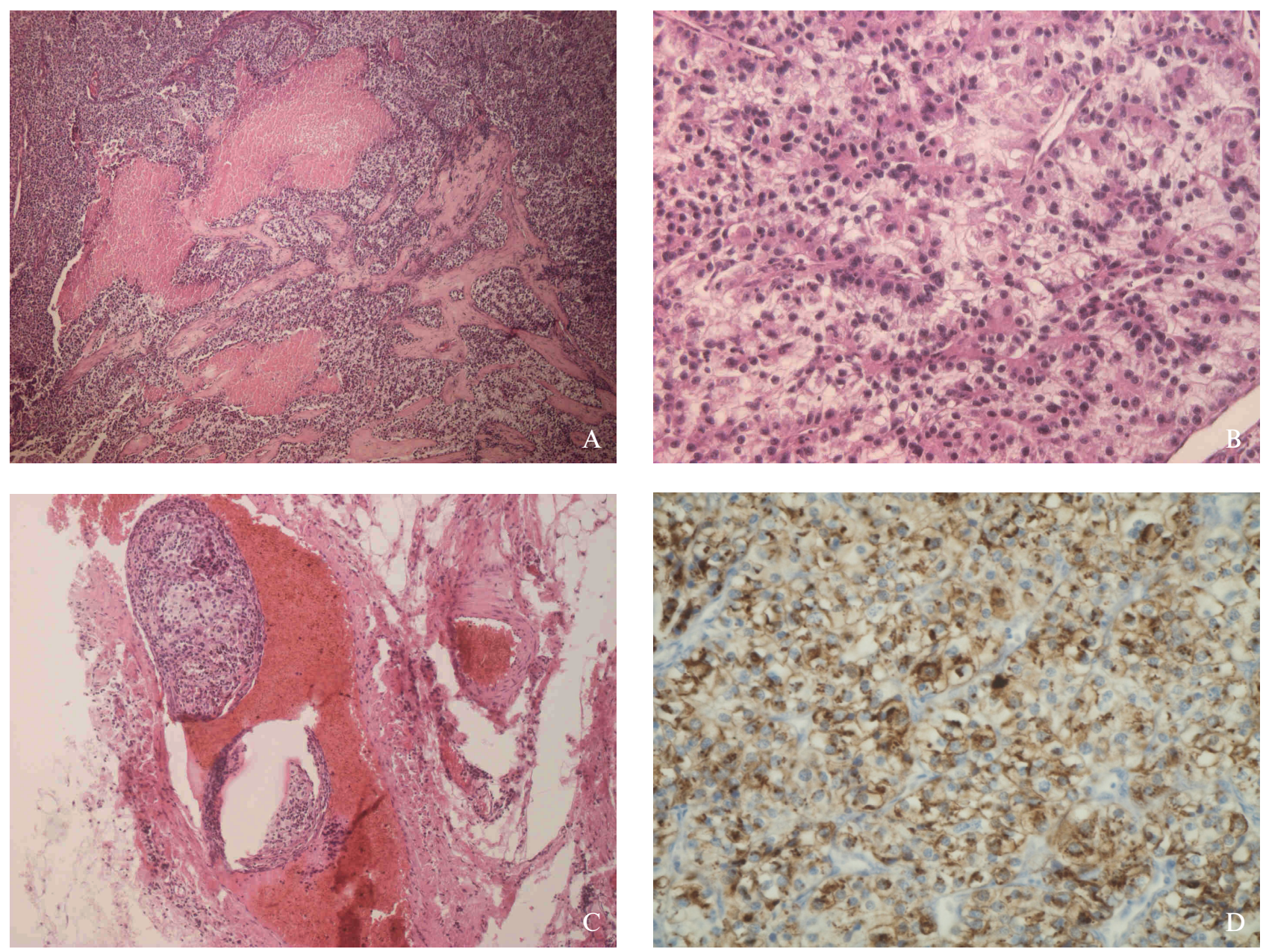

Fig. 1. Histology of parathyroid carcinoma. (A) On histological examination of the primary tumor solid carcinoma with areas of necrosis and fibrous septa was evident (hematoxylin-eosin staining, original magnification 40x. (B) Part of the tumor section with trabecular and rosette-forming cells with clear or eosinophil cytoplasm and low mitotic activity (hematoxylin-eosin staining, original magnification 200x). (C) Angioinvasion of the tumor (hematoxylin-eosin staining, original magnification 100x). (D) Immunohistochemical staining of tumor cells for parathormone (original magnification 400x).

\section{FDG PET}
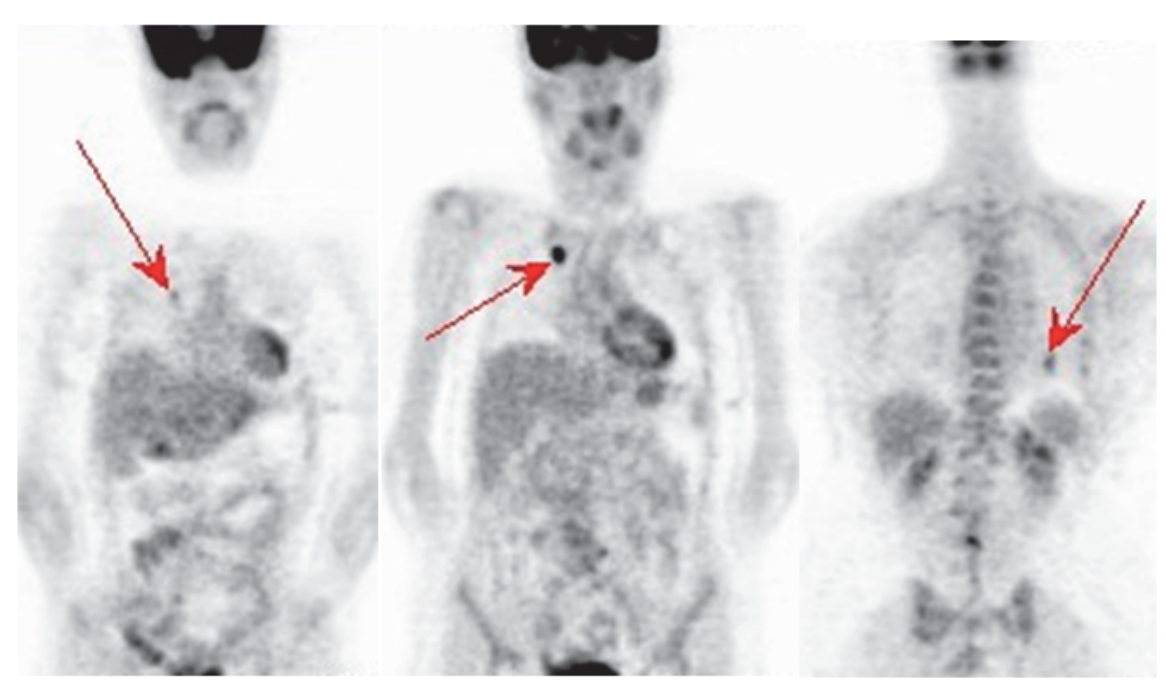

Fig. 2. Visualization of lung metastases by $\left[{ }^{18} \mathrm{~F}\right]$ fluorodeoxyglucose (FDG) positronemission tomography (PET). FDG PET in May 2007 demonstrated multiple metastases bilaterally in the lungs (arrows). 

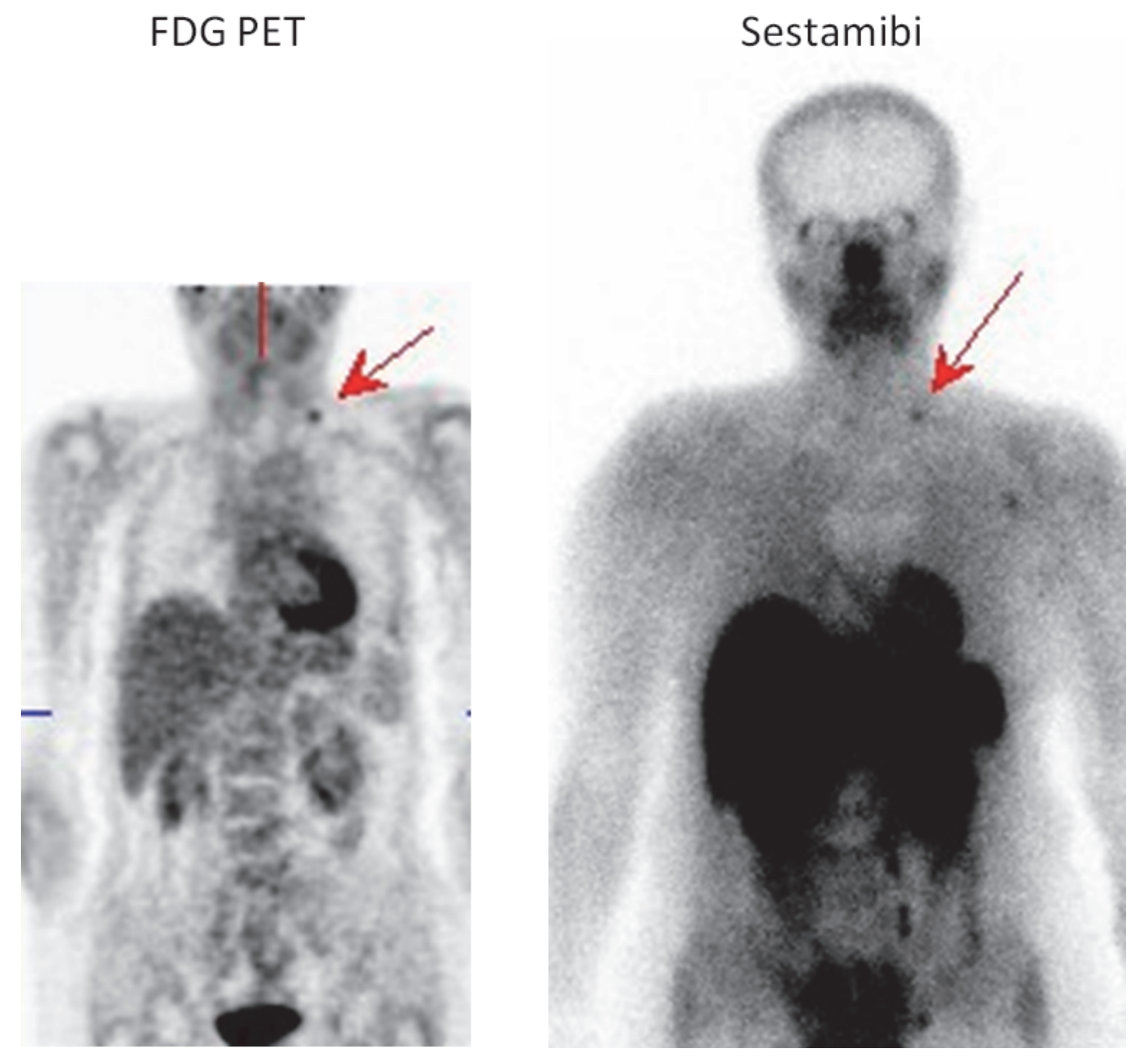

Fig. 3. Visualization of solitary cervical lymph node metastasis by $\left[{ }^{18} \mathrm{~F}\right]$ fluorodeoxyglucose positron-emission tomography and ${ }^{99 m}$ technetium-sestamibi scan. After thoracoscopic resection of the lung metastases, control FDG PET (left) and ${ }^{99 \mathrm{~m}}$ technetium-sestamibi scan (right) showed solitary metastasis in a left neck lymph node (January 2008)

resection of two metastases in the right lung and, in a separate procedure, thoracoscopic resection of the lung metastasis in the left lung a month later. Histological examination of lung metastases was consistent with metastatic parathyroid carcinoma.

The control PET/CT in January 2008 showed only the metastasis in a left neck lymph node (Fig. 3). Similar findings were obtained with ${ }^{99 \mathrm{~m}}$ technetium-sestamibi scan. The serum concentration of parathyroid hormone was slightly elevated $(80 \mathrm{ng} / \mathrm{L})$, while serum calcium and alkaline phosphatase levels were within the normal range. Between March and June 2008 the patient was treated with 4 cycles of systemic chemotherapy using regimen that combined cisplatin and 5-fluorouracil. Subsequent PET/CT in July 2008 demonstrated mild progression of the size of the cervical lymph node metastasis.

On October 9, 2008, the patient presented with confusion and hypertensive crisis. Brain CT scans revealed multiple metastatic lesions in both hemispheres. These findings were confirmed by magnetic resonance imaging. In addition, a lesion in the right orbit was detected. ${ }^{99 \mathrm{~m}}$ technetium-sestamibi scan revealed brain metastases, metastasis in the right orbit and involvement of bilateral supraclavicular lymph nodes (Fig. 4). Similar findings were observed on PET/CT. The parathyroid hormone concentration, serum calcium concentration and alkaline phosphatase activity were $445 \mathrm{ng} / \mathrm{L}, 4.03 \mathrm{mmol} / \mathrm{L}$ and $3.68 \mu \mathrm{kat} / \mathrm{L}$ (normal range $2.15-5.0 \mu \mathrm{kat} / \mathrm{L}$ ), respectively. Supportive therapy that included intravenous fluids, zolendronic acid, dexamethasone and diuretics was instituted, and the patient was treated by whole brain irradiation using ${ }^{60} \mathrm{Co} 30.0 \mathrm{~Gy}$ five times weekly in fractions of $3.0 \mathrm{~Gy}$. Because of poor performance status the patient was subsequently treated only symptomatically with the medication outlined above and died on December 3, 2008.

\section{DISCUSSION AND REVIEW OF THE LITERATURE}

We report here a rare patient with parathyroid carcinoma, who had lung and cervical lymph node metastases that were diagnosed almost synchronously with the radical surgical resection of the tumor. The tumor manifested with dysphonia and neck mass, but no biochemical signs of disease activity were noted at the time of initial diagnosis. The patient was initially treated with doxorubicin monotherapy that resulted in a partial response that made possible subsequent surgical resection of the lung metastases. Because of the recurrence in cervical lymph nodes, the patient was treated with second-line chemotherapy using the combination of cisplatin and 5-fluorouracil. Four months after completion of the second-line treatment, 

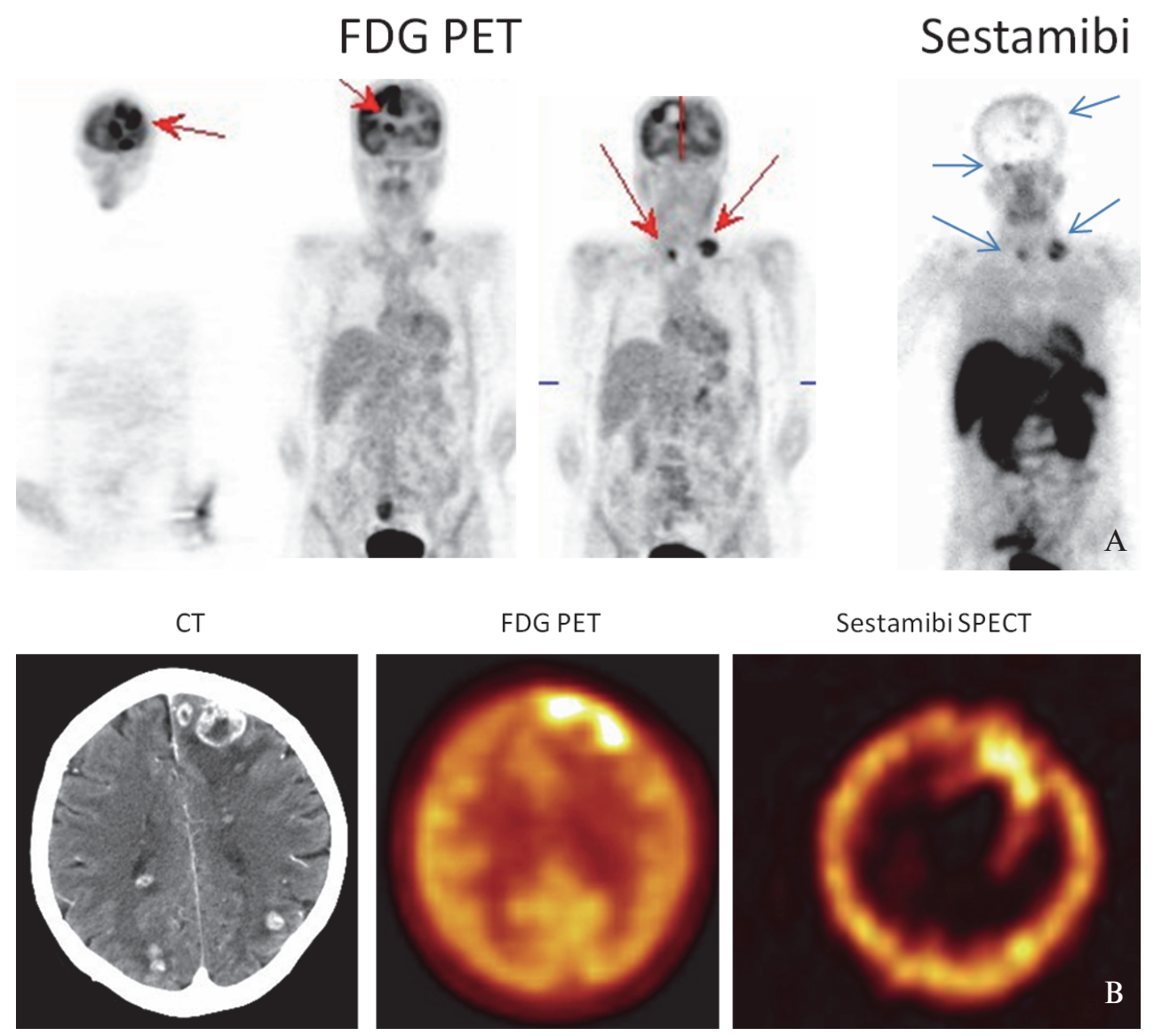

Fig. 4. Visualization of disease progression by $\left[{ }^{18} \mathrm{~F}\right]$ fluorodeoxyglucose positron-emission tomography and ${ }^{99 \mathrm{~m}}$ technetium-sestamibi scan. FDG PET (A) in October 2008 revealed brain metastases, metastasis in the right orbit and the involvement of bilateral supraclavicular lymph nodes (red arrows). Similar findings were noted on ${ }^{99} \mathrm{~m}$ technetium-sestamibi scan (blue arrows). (B) CT (left), PET (middle) and ${ }^{99 \mathrm{~m}}$ technetium-sestamibi SPECT (right) demonstrated metastatic lesions in the left hemisphere.

the patient presented with severe hypertension and confusion and was diagnosed with brain metastases. Despite radiation therapy and supportive treatment that included the administration of bisphosphonates, the patient died within 2 months after the diagnosis of brain metastases. The progression of the disease was associated with increased concentrations of tumor biomarkers, including serum calcium and parathyroid hormone. In the present case, the metastases in the brain, orbit and lymph nodes could also be detected by $\left[{ }^{18} \mathrm{~F}\right]$ FDG PET/CT and by ${ }^{99 \mathrm{~m}}$ technetium-sestamibi uptake. ${ }^{99 \mathrm{~m}}$ technetium-sestamibi scan is commonly used for parathyroid localization but experience using this method for the localization of metastatic disease is limited, owing to the rarity of distant metastases in this uncommon tumor ${ }^{5}$. The detection of brain metastases of parathyroid carcinoma using ${ }^{99 \mathrm{~m}}$ technetium-sestamibi is exceptional. However, only the larger brain metastases were evident on ${ }^{99}$ technetium-sestamibi and PET/CT scans, while additional smaller lesions were detectable only on CT scan.

Although parathyroid carcinoma follows, in general, a relatively indolent clinical course, the tumor recurs locally, either in the soft tissues of the neck or in regional cervical lymph nodes, in $40-60 \%$ of patients, usually within 3 years after initial surgery. In addition, cases of late recurrence have also been described. In contrast, distant hematogenous metastases are less common, being reported in about $25 \%$ of patients, most commonly in the lungs, but occasionally also manifesting in the bone, liver, pleura, pericardium, or pancreas ${ }^{2,4}$. Synchronous metastases in patients with parathyroid carcinoma are rare. In a pooled analysis of 301 patients reported in the literature, synchronous metastases were reported only in 9 patients (3\%) $\left(\right.$ ref. $\left.^{3}\right)$.

As in the present case, parathyroid carcinomas frequently produce high levels of parathyroid hormone, accompanied by marked elevation of serum calcium with associated renal and bone symptoms. Symptoms of hypercalcemia range from anorexia, nausea, vomiting, fatigue, weakness, polyuria and polydipsia to manifestations of renal disease including renal stones, nephrocalcinosis, and renal failure ${ }^{2-4}$. Patients with parathyroid carcinoma may present with extreme hypercalcemia and hypercalcemic crisis manifesting by a decreased level of consciousness and dehydration. Other symptoms characteristic of hyperparathyroidism include bone pain and fractures. Many patients die from complications associated with hyperparathyroidism, mainly hypercalcemia, rather than 
Table 1. Cases of parathyroid carcinoma brain metastases reported in the literature.

\begin{tabular}{|c|c|c|c|c|c|c|c|}
\hline Ref. & $\begin{array}{l}\text { Age at diag- } \\
\text { nosis of brain } \\
\text { metastasis } \\
\text { (years) and sex } \\
(\mathrm{F}, \mathrm{M})\end{array}$ & $\begin{array}{l}\text { Interval between di- } \\
\text { agnosis of parathy- } \\
\text { roid carcinoma and } \\
\text { brain metastases }\end{array}$ & $\begin{array}{l}\text { Location } \\
\text { of brain } \\
\text { metastases }\end{array}$ & $\begin{array}{l}\text { Other meta- } \\
\text { static sites }\end{array}$ & $\begin{array}{l}\text { Symptoms of brain } \\
\text { metastases }\end{array}$ & $\begin{array}{l}\text { Treatment } \\
\text { of brain } \\
\text { metastases }\end{array}$ & Outcome \\
\hline 6 & $56,(\mathrm{~F})$ & 22 months & $\begin{array}{l}\text { Frontal } \\
\text { (solitary) }\end{array}$ & $\begin{array}{l}\text { Liver, medias- } \\
\text { tium, abdomi- } \\
\text { nal LN, bone }\end{array}$ & $\begin{array}{l}\text { Headache, nausea, } \\
\text { vomiting, hemipa- } \\
\text { resis }\end{array}$ & Resection & $\begin{array}{l}\text { Died of extracra- } \\
\text { nial disease after } \\
8 \text { months }\end{array}$ \\
\hline 7 & $61,(\mathrm{~F})$ & 18 years & $\begin{array}{l}\text { Frontal } \\
\text { ( } 2 \text { lesions) }\end{array}$ & Lungs, pleura & $\begin{array}{l}\text { Hemiparesis, } \\
\text { hemihypestesia, } \\
\text { hypercalcemia }\end{array}$ & Resection & $\begin{array}{l}\text { Alive, no } \\
\text { evidence of brain } \\
\text { metastases after } \\
11 \text { months }\end{array}$ \\
\hline 8 & 48, (M) & 4 years & $\begin{array}{l}\text { Fronto- } \\
\text { parietal } \\
\text { (solitary) }\end{array}$ & None & $\begin{array}{l}\text { Lower-extremity } \\
\text { weakness, hyper- } \\
\text { calcemia }\end{array}$ & $\begin{array}{l}\text { Resection, } \\
\text { adjuvant } \\
\text { radiotherapy }\end{array}$ & $\begin{array}{l}\text { Alive, no evi- } \\
\text { dence of disease } \\
\text { after } 18 \text { months }\end{array}$ \\
\hline 9 & $54,(\mathrm{~F})$ & 9 years & $\begin{array}{l}\text { Occipital } \\
\text { (solitary) }\end{array}$ & $\begin{array}{l}\text { Neck, medias- } \\
\text { tinum, lung }\end{array}$ & $\begin{array}{l}\text { Hemianopsia, } \\
\text { hypercalcemia }\end{array}$ & Resection & $\begin{array}{l}\text { Surgery for recur- } \\
\text { rent lesion after } \\
2 \text { months }\end{array}$ \\
\hline $\begin{array}{l}\text { Present } \\
\text { case }\end{array}$ & 64, (F) & 18 months & $\begin{array}{l}\text { Multiple, } \\
\text { bilateral }\end{array}$ & $\begin{array}{l}\text { Lungs, neck } \\
\text { LN, orbit }\end{array}$ & $\begin{array}{l}\text { Confusion, hy- } \\
\text { pertensive crisis, } \\
\text { hypercalcemia }\end{array}$ & $\begin{array}{l}\text { Radio- } \\
\text { therapy }\end{array}$ & $\begin{array}{l}\text { Died of disease } \\
2 \text { months later }\end{array}$ \\
\hline
\end{tabular}

from tumor growth. Increased serum concentrations of calcium or parathyroid hormone serve as biomarkers of tumor activity, and an increase in these laboratory parameters precedes, in most cases, the detection of recurrent disease by imaging studies. As metabolic and neurological complications represent a significant cause of death from parathyroid carcinoma, surgical debulking to eliminate parathyroid hormone-secreting malignant tissue may play a role in the management of patients with metastatic disease $^{3}$. Resection of distant metastases may also improve prognosis ${ }^{3}$. On the other hand, chemotherapy and radiotherapy have a limited role in the palliative management of the patient with unresectable disease. Medical treatment may control hypercalcemia, but, as in the present case, the extent of metastatic disease may be the most important factor determining patient prognosis.

Intracranial metastases from parathyroid carcinoma are exceptional. A comprehensive review of the literature revealed only 4 more cases of parathyroid carcinoma brain metastases (Table 1) (ref. $\left.{ }^{6-9}\right)$. Unlike the present case, all cases of brain metastases of parathyroid carcinoma reported so far could be treated surgically. Despite aggressive surgical treatment, the tumor recurred rapidly in two patients and the follow-up was relatively short in the remaining two cases. Although most of the patients had solitary brain lesions, only one patient had no extracranial disease. Only in one of these patients was the brain metastasis localized using ${ }^{99 \mathrm{~m}}$ technetium-sestamibi scans ${ }^{8}$.

Given the paucity of published data on this topic, the diagnostic and therapeutic approach in the cases of brain metastases of parathyroid carcinoma can be determined only by expert recommendations. As a consequence of probable publication bias, cases that were considered to represent a therapeutic success were possibly more likely to be published than cases when the therapy was not successful like the present case. Imaging studies in the case of suspected metastases of parathyroid carcinoma should certainly include ${ }^{99 \mathrm{~m}}$ technetium-sestamibi scan. In contrast to some other endocrine tumors, there is no effective targeted treatment for advanced parathyroid carcinoma, and systemic therapy has, at best, only a limited role in the management of patients with metastatic parathyroid carcinoma ${ }^{10}$, especially in cases with brain metastases. Surgery should be attempted in the case of isolated solitary metastatic lesions, including brain metastases. In fact, all prior reports of brain metastases of parathyroid carcinoma indicate some utility of surgery in this setting. However, the use of radiotherapy in patients with parathyroid carcinoma metastatic to the brain seems to be, like the case presented here, limited to palliation. Thus, therapeutic options in the case of parathyroid carcinoma brain metastases seem to be limited.

In conclusion, the present case demonstrates that parathyroid carcinoma may have an aggressive pattern of behavior, including the formation of brain metastases early after the initial diagnosis. $\left[{ }^{18} \mathrm{~F}\right] \mathrm{FDG}$ PET/CT and ${ }^{99 m}$ technetium-sestamibi scan may be useful in localizing parathyroid carcinoma metastases, including brain metastases. There is currently no effective therapy in these cases with the exception of resection in cases of isolated solitary metastases. 


\section{ACKNOWLEDGEMENT}

Supported by the Research Projects LO1304 and RVO61989592.

Author contributions: All authors contributed to the manuscript and approved the final version.

Conflict of interest statement: The authors state that there are no conflicts of interest regarding the publication of this article.

\section{REFERENCES}

1. Hundahl SA, Fleming ID, Fremgen AM, Menck HR. Two hundred eighty-six cases of parathyroid carcinoma treated in the U.S. between 1985-1995. A National Cancer Data Base report. Cancer 1999;86:538-44.

2. Cordeiro AC, Montenegro FLM, Kulcsar MAV, Dellanegra LA, Tavares MR, Michaluart P, Ferraz AR. Parathyroid carcinoma. Am J Surg 1998;175:52-5.
3. Koea JB, Shaw JHF. Parathyroid cancer: biology and management. Surg Oncol 1999;8:155-65.

4. Busaidy NL, Jimenez C, Habra MA, Schultz P, El-Naggar AK, Clayman GL, Asper JA, Diaz EM Jr, Evans DB, Gagel RF, Garden A, Hoff AO, Lee JE, Morrison WH, Rosenthal DI, Sherman SI, Sturgis EM, Waguespack SG, Weber RS, Wirfel K, Vassilopoulou-Sellin R. Parathyroid carcinoma: A 22-year experience. Head Neck 2004;26:716-26.

5. Al-Sobhi S, Ashari LH, Ingemansson S. Detection of metastatic parathyroid carcinoma with Tc-99m sestamibi imaging. Clin Nucl Med 1999:24:21-3

6. Kern M, Lee G, Robbins P, Bynevelt M, Watson P. Intracranial metastatic parathyroid carcinoma. Case report and review of literature. J Neurosurg 2004;101:1065-9.

7. Yoshida S. Intracranial metastatic parathyroid carcinoma: case report. Surg Neurol 2006;65:81-3.

8. Tyler D, Mandybur G, Dhillon G, Fratkin J. Intracranial metastatic parathyroid carcinoma: case report. Neurosurgery 2001;48:937-40.

9. Yamamoto T, Matsumura A, Fujita K, Kawakami Y, Yamashita K, Nose T. Cerebral metastasis of parathyroid carcinoma. Neurol Med Chir (Tokyo) 1996;36:96-8.

10. Wei $\mathrm{CH}$, Harari A. Parathyroid carcinoma: update and guidelines for management. Curr Treat Options Oncol 2012;13:11-23. 